\title{
ANA MERCEDES HOYOS
}

\section{Juan Gustavo Cobo Borda}

Ana Mercedes Hoyos comenzó a mirar el mundo desde una ventana. Era una ventana aséptica, fría, que daba sobre un esquemático paisaje urbano: la línea blanca pautando el asfalto, el muro rosa bloqueando la visión, las letras enigmáticas de alguna tipografía citadina apenas sugerentes e incitándonos a leer con la misma mirada de la artista. No mensajes sino signos apenas.

Pero pronto limpió el escenario y esos fragmentos recortados, esos ángulos de tajantes esquinas, se volvían atmósfera. Solo atmósfera a partir de una indagación en el color. En la delgada lámina con que la atmósfera envuelve nuestra visión. Simple atmósfera que se desvanece y hierve en azules. En la blanca reverberación de todos los colores. No había más que pintura, capa tras capa.

Era como si el lienzo se hubiese tensado y sacudido arrojando todos los referentes materiales, y se hubiese vuelto blanco absoluto. Sobre él pudo iniciar entonces su aprendizaje de la historia del arte: bode- gón de Caravaggio, frutas de Zurbarán, vibrantes flores de Jawlenski en acompasados planos de rojo y azul y, claro está, los girasoles de Van Gogh que se reiteraban, obsesivos como su locura, en el zócalo de la galería. Podría hablarse incluso de una abstracción conceptual. Pero había deleite en el modo en que descubría y recomponía el núcleo duro de un girasol. Intensidad que enceguece. Un punto de negra y sólida materia en ignición; terminó por erguirlo como un tótem elocuente de madera y hierro en medio de los ladrillos de Rogelio Salmona. En cierto modo también lo suyo había sido una exploración arquitectónica, sobre los cuadrantes geométricos de ese reloj natural que mide el periplo de la luz.

Desmesurados primeros planos, en la absorbente atención fotográfica de un close-up. Con todo ello armaría su serie emblemática: de las playas de Cartagena al mercado de Bazurto, las vendedoras de frutas de San Basilio de Palenque. San Basilio de Palenque, primer territorio libre 
de América, con lengua propia, que en la época colonial crearon esclavos cimarrones que huían de los amos españoles. De la cruz de la fe y el hierro de la Inquisición. Sus fiestas, sus héroes como Benko Biohó, su lucha por seguir siendo ellos mismos y no perder sus raíces africanas, aún subsisten.

Sólo que Ana Mercedes Hoyos, como buena artista del liso y primer plano en terso color, se fijó ante todo en sus blancas palanganas, en sus frágiles butacos, en la remota línea de la espuma del mar. Sobre dicho entramado de referencias locales dispuso la negra infinitud de sus pieles robustas, el deleite holgado de sus amplias polleras y el corte contrastante de ese azul ondulante con la vibración amarilla de la camiseta que ceñía su opulento busto. Grandes masas plásticas, de piernas abiertas, ofreciendo la cornucopia jugosa de su sensualidad. Ahora la ventana se había vuelto la panorámica infinita de la playa cuyo punto focal de resistencia era esa mujer sola pelando con su sólido cuchi- llo, en las primeras horas de la mañana, la ensalada de frescas frutas para el turista.

Contrapunto de naturaleza e historia, de reflexión estética y antropología ecológica. Sandías, papayas, plátanos, armados en asombroso equilibrio sobre esas cabezas altas de andar melódico. Ritmo de la oferta y el pregón al cual hacían eco la sinfonía de colores comestibles. El mestizaje barroco de esas ofrendas que como las kores griegas también rinden homenaje a la fertilidad de la tierra. Aquí no había estaciones: - como dijo el poeta Eugenio Montejo-, sólo el trópico absoluto. Luz que inmoviliza el conjunto, sin sombras, sin subterfugios, en el hermoso perfil. En el airoso desafío de esa belleza escueta con que también Picasso aprendió a pintar, gracias a las máscaras africanas de Las señoritas de Aviñón. Pero aquí estamos en el Caribe y Ana Mercedes Hoyos es el heraldo que proclama la riqueza de una cultura propia y de una pintura memorable. 